\title{
A Ray of Sunshine: Transparency in Physician-Industry Relationships Is Not Enough
}

\author{
Joel Lexchin, MSc, $M D^{1,2,3}$ and Adriane Fugh-Berman, $M D^{4}{ }_{(1)}$ \\ ${ }^{1}$ School of Health Policy and Management, York University, Toronto, ON, Canada; ${ }^{2}$ University Health Network, Toronto, Canada; ${ }^{3}$ Faculty of \\ Medicine, University of Toronto, Toronto, Canada; ${ }^{4}$ Department of Pharmacology and Physiology, Georgetown University Medical Center, \\ Washington, DC, USA.
}

Gifts from pharmaceutical and medical device companies to physicians in the United States have been reported since 2014, through the Physician Payments Sunshine Act. Although researchers have utilized these data to publish many studies on conflicts of interest (COIs) and prescribing behavior, there is no evidence that physician behavior regarding $\mathrm{COI}$ has changed, or that employers, meeting organizers, or medical journals are excluding physicians based on conflicts of interest. Disclosure is necessary but not sufficient to address the damage that industry relationships causes to medical knowledge and public health.

J Gen Intern Med 36(10):3194-8

DOI: $10.1007 / \mathrm{s} 11606-021-06657-0$

c) Society of General Internal Medicine 2021

$\mathrm{T}$ he United States (U.S.) Physician Payments Sunshine Act, part of the Affordable Care Act, mandates that pharmaceutical and medical device companies report gifts or any other transfer of value of US $\$ 10$ or greater to physicians to the Centers for Medicare and Medicaid Services. ${ }^{1}$ The information is then available in a public database.

The Act's implementation in September 2014 generated great anticipation about its benefits. Authors of an essay in the New England Journal of Medicine noted that the Act could potentially change the behavior of both physicians and patients. ${ }^{1}$ Another commentator foresaw that “... medical school deans, hospital administrators, and leaders of professional medical societies will be able to consult the data when making teaching assignments, appointing formulary committees, establishing practice guideline committees or selecting speakers and commentators", and noted that medical journal editors, journalists, and patients could also use the information to evaluate physicians. $^{2}$

The concept caught on: several European countries and Australia also adopted similar laws or, in some cases, industry

Received November 9, 2020

Accepted February 8, 2021

Published online March 10, 2021 associations voluntarily agreed to provide similar information. ${ }^{3,4}$ However, there are differences among countries. For example, in the United Kingdom, individual doctors can opt out from having their data released. In Australia, companies do not have to report the value of meals. The Canadian province of Ontario was on the verge of enacting an even more comprehensive piece of legislation ${ }^{5}$ until the government changed as a result of an election. ${ }^{6}$

\section{WHAT THE SUNSHINE ACT REVEALED}

Has disclosure made a difference? The U.S. legislation has certainly been a boon for researchers examining conflicts of interest (COIs) and prescribing behavior. Dozens of articles using Open Payments data have been published, including national analyses of gift acceptance among physicians, ${ }^{7}$, ${ }^{8}$ and many analyses of payments within multiple specialties, including oncologists,${ }^{9}$ neurologists, ${ }^{10}$ cardiologists, ${ }^{11}$ thoracic surgeons, ${ }^{12}$ and ophthalmologists. ${ }^{13}$

Open Payments has enabled numerous studies of discrepancies between disclosures of conflicts of interest and reported payments. ${ }^{14}$ Other analyses have examined payments to contributors to clinical guidelines, ${ }^{15,16}$ medical journal editors, ${ }^{17,} 18$ and leaders of professional organizations. ${ }^{19}$

The combination of data from the Open Payments database and prescribing information from Medicare Part D revealed that industry gifts, including meals and speaking, consulting, and other financial opportunities, influence physicians' therapeutic choices. Meals and other small gifts increased prescriptions for targeted drugs, compared to competing drugs, in four different drug classes. ${ }^{20} \mathrm{~A}$ large study of over 150,000 physicians found that those who received any gifts - even a few meals - from drug or device manufacturers prescribed a higher percentage of branded drugs and devices overall than physicians who received no gifts. ${ }^{21}$ Industry payments to physicians are associated with increased prescribing of branded drugs ${ }^{7}$, 8 including expensive branded drugs with uncertain medical benefit, ${ }^{22}$ and reduced prescribing of generic drugs. ${ }^{23}$ Marketing of opioid products to physicians was associated with increased opioid prescribing. ${ }^{10,24}$ 


\section{WHAT HAS TRANSPARENCY WROUGHT?}

As the Sunshine Act was being implemented, there was already skepticism about how successful it was going to be in curtailing the influence of financial COI. Drawing an analogy with Wall Street, Wilson pointed out that decades of market scandals there had revealed a long history of compromised auditor independence arising from consultancies with corporate clients. The attempt to manage the problem by disclosing these conflicts failed to prevent further scandals involving tainted accounting audits, as the 2008 global financial crisis highlighted. $^{25}$

\section{No Change in Behavior in the Medical Profession}

Despite robust, consistent results showing that payments to physicians degrade rational prescribing, there is no evidence that physician behavior regarding conflicts of interest has changed. No effective policies have been enacted to restrict financial COI. Medical journals don't use Open Payments to vet authors or reviewers. And universities do not sanction physicians for COI.

Perhaps this lack of movement should not be a surprise. Apathy towards COIs is not new. Long before the Sunshine Act, interviews of active clinical investigators at the University of California at San Francisco and at Stanford University $^{26}$ found that less than half could accurately describe their institution's conflict-of-interest policy. Virtually the same situation existed in Australia; most Fellows of the Royal Australian College of Physicians (RACP) had not used the ethical guidelines of the RACP regarding relationships with the pharmaceutical industry; ${ }^{27}$ very few had even read or referred to them.

There does not seem to be a diminution in payments to physicians in the 5 years since the Sunshine Act came into effect; contributions to doctors from 20 top-spending medical technology companies collectively more than tripled. ${ }^{28}$ In the ophthalmology community, increasing requirements for disclosure of financial relationships by participants at the annual meeting of the American Academy of Ophthalmology between 2008 and 2015 was not associated with a decrease in financial disclosures associated with potentially beneficial physician-industry ties. In addition, the percentage of participants with at least one financial disclosure and the mean number of disclosures per participant increased over the time period. ${ }^{29}$ This finding accords with social science studies, which have found that disclosure may enhance bias among presenters, who feel they have free reign to present industryfriendly information after having disclosed a COI. ${ }^{30}$

\section{No Change in Consumer and Patient Behavior}

Wilson argued that the public is not skilled enough to evaluate the implications of payments and that the Act "mythologizes transparency". ${ }^{25}$ Evidence supports the fact that consumers rarely seek information about physicians, even when such information is crucial to their health. For example, consumers are unaware of available data on provider quality, including data about predicted mortality rates associated with different cardiothoracic surgeons. ${ }^{31}$ Even when they are aware of these data, they "tend to choose their providers on the basis of other factors". ${ }^{1}$

Out of 1987 respondents from a large, nationally representative U.S. household panel, only $12 \%$ knew that payment information was publicly available, and only $5 \%$ knew whether their own doctor had received payments. ${ }^{32}$ A study of patients' perceptions of their orthopedic surgeons' industry relationships found that few were aware of the relationships, but when made aware, most patients viewed these relationships as being neutral or positive. ${ }^{33}$

The infrequent use of the available data probably reflects patients' forgiving attitudes about the effect of financial COI. While industry payments affected patients' perceptions of honesty and fidelity in individual physicians, viewing an online disclosure database did not affect their trust ratings for the medical profession or the pharmaceutical industry. ${ }^{34}$ Most patients in cancer research trials were not worried about relationships between researchers and drug companies and stated that would still have enrolled in the trial if they had known about these relationships. ${ }^{35}$ The belief that a clinical trial offered the best care appeared to outweigh concerns about conflicts; some patients expressed confidence in institutional oversight of conflicts. ${ }^{35}$

\section{TRANSPARENCY IS NOT ENOUGH}

At the PharmedOut conference in 2017, Dr. Lisa Cosgrove concluded that "transparency is an insufficient solution to the problem of the corruption of the evidence base because it can't guard against implicit bias, and may even be dangerous". ${ }^{36}$ The comment echoes the opinion of former New England Journal of Medicine editor, Jerome Kassirer, who critiqued the fixation on "the wrong problem", i.e., the lack of transparency and "expressed concern that the need to eliminate commercial conflicts, especially from oversight bodies that assess the integrity of medical data, was being excluded as a public policy option". 25

Transparency in the form of disclosure may actually enhance the uptake of marketing messages. Disclosure of a conflict of interest, paradoxically, increases trust in the speaker, who is now viewed as an honest, forthright person. For a presenter or author, disclosure provides both moral licensing and a concrete reason to present biased information. Disclosure may motivate a speaker to exaggerate the benefits or underplay the harms of a particular treatment because the speaker expects the information to be discounted. In fact, people informed of conflicts do not 
discount information as much as they should. ${ }^{30}$ Disclosure, however, does not cleanse tainted information, straighten distorted perspectives, or filter out marketing messages. Disclosure may lull audiences into believing, wrongly, that they can extract unbiased information from a biased presenter.

Research shows that disclosure of COI is most likely to be useful when recipients of the disclosure have access to an alternative. ${ }^{37}$ A patient in a physician's office, especially if the two have an established relationship, may not feel he or she has an alternative. A conference attendee is not given the choice of conflict-laden talks in Ballroom A and conflict-free talks in Ballroom B.

\section{THE NEXT STEPS}

Transparency is necessary but not sufficient. In fact, it should be expanded to include a wider range of healthcare professionals, institutions, and organizations and make disclosure mandatory in jurisdictions where it is not. Next, there needs to be a serious effort to eliminate financial COI, partly drawing on proposals that already exist. Measures at the level of medical schools and residency programs to decrease interactions between students and trainees and pharmaceutical companies have made physicians less susceptible to industry influence once they are in independent practice. ${ }^{38-40}$

In 2006, Brennan and colleagues proposed a series of reforms for academic medical centers including the elimination of all gifts, free meals, payment for time for travel to or time at meetings, and payment for participation in online continuing medical education (CME). They also recommended the prohibition of direct provision of pharmaceutical samples to physicians, excluding physicians with financial relationships with drug manufacturers from hospital and medical group formulary committees and banning faculty at academic centers from serving as members of speakers bureaus for pharmaceutical or device manufacturers. ${ }^{41}$

The U.S. Institute of Medicine (now the National Academy of Medicine, NAM) formulated a set of recommendations in its 2011 report on the creation of guidelines. ${ }^{42}$ Specifically, with respect to managing conflicts of interest, the NAM recommended that prior to their selection each panel member should explain how his or her COI could influence the clinical practice guideline development process or specific recommendations; members of the guideline development group should divest themselves of financial investments they or their family members have in entities whose interests could be affected by guideline recommendations; members with COIs should represent not more than a minority of the committees; and the chair or cochairs should not have any COI.
Whenever possible, guideline committees should be constituted by governments and not-for-profit groups. Guideline groups originating from these sources have a much smaller percentage of conflicted members than committees formed by medical specialty societies and professional associations ${ }^{43}$ and the former should be strongly preferred when it comes to the creation of new guidelines.

Professional conferences and meetings should include a majority of speakers without COIs and should consider disallowing any speaker with a COI. Continuing medical education should be delivered without any commercial involvement. The Accreditation Council on Continuing Medical Education claims that it safeguards CME from commercial influence, ${ }^{44}$ but it has failed to do so. Although the Council claims that $90 \%$ of CME activities are not commercially supported, the organization does not count in-kind industry contributions of equipment, supplies, facilities, or other resources, nor does it count advertising and exhibits income, and they have no restrictions on industry connections with faculty (in fact, industry employees are even allowed to control CME content). ${ }^{45}$

Since 2005, the Society for General Internal Medicine has declined to accept funding from for-profit companies for research or educational projects at its national or regional meetings. ${ }^{46}$ In 2008, the 1300-member Oregon chapter of the Academy of Family Physicians decided to no longer accept any grants - restricted or unrestricted - for its continuing education seminars or allow drug companies to have booths in its exhibit hall during conferences. ${ }^{47}$ The College of Family Physicians of Canada has announced that it will phase out all funding from pharmaceutical industry sources for its annual scientific conference by $2024 .^{48}$ Many U.S. agencies and Washington D.C. provide online CME free of COI, as does the Therapeutics Initiative in British Columbia, Canada. PharmedOut, an independent non-governmental organization based at Georgetown University, maintains a list of industryfree CME provided by government, non-profit organizations, and other entities at http://pharmedout.org.

All of these changes need to be accompanied by strong and ongoing endorsement from the leadership in the medical community and by measures to promote them at the international, national, and local levels.

\section{CONCLUSION}

Financial COI is corrosive and eats away at the basic function of medicine - to deliver quality care to patients. Declaring conflicts is only the first step in dealing with this problem. Philosopher Carl Elliott has exposed the false solution of transparency by comparing it to an extramarital affair, asking, if your spouse were having an affair, is the situation resolved 
once the disclosure is made? Is it enough to disclose the affair, or do you want your spouse to end it? It is an apt analogy. Disclosure is not enough. The ultimate solution is to eliminate all industry relationships from the practice of medicine.

Corresponding Author: Adriane Fugh-Berman, MD; Department of Pharmacology and Physiology, Georgetown University Medical Center, Washington, DC, USA (e-mail: aif29@georgetown.edu).

\section{REFERENCES}

1. Rosenthal MB, Mello MM. Sunlight as disinfectant - new rules on disclosure of industry payments to physicians. N Engl $\mathrm{J}$ Med. 2013;368(22):2052-4.

2. Rothman DJ. Here comes the sun. Milbank Q. 2014;92(3):471-4.

3. Fabbri A, la Santos A, Mezinska S, Mulinari S, Mintzes B. Sunshine policies and murky shadows in Europe: disclosure of pharmaceutical industry payments to health professionals in nine European countries. Int J Health Policy Manag. 2018;7(6):504-9.

4. Grundy $\mathbf{3}$, Habibi R, Shnier A, Mayes C, Lipworth W. Decoding disclosure: comparing conflict of interest policy among the United States, France, and Australia. Health Policy. 2018;122(5):509-18.

5. Grant K. Ontario to force pharmaceutical companies to disclose money paid to doctors. Globe and Mail [Internet]. 2017 Sept 27 [cited $2021 \mathrm{Mar}$ 4]. Available from: https://www.theglobeandmail.com/news/national/ ontario-to-force-pharmaceutical-companies-to-divulge-payments-to-doctors/article36406998/.

6. Grant K. Ford PCs leave drug-company transparency law in limbo. Globe and Mail [Internet]. 2018 Nov 5 [cited 2021 Mar 4]. Available from: https://www.theglobeandmail.com/canada/article-ford-pcs-leave-drugcompany-transparency-law-in-limbo/.

7. Garstka ME, Monlezun D, DuCoin C, Killackey M, Kandil E. The Sunshine Act and surgeons: a nation-wide analysis of industry payments to physicians. J Surg Res. 2019;233:41-9.

8. Inoue K, Blumenthal DM, Elashoff $\mathbf{D}$, Tsugawa Y. Association between physician characteristics and payments from industry in 2015-2017: observational study. BMJ Open. 2019;9(9):e031010.

9. Marshall DC, Moy B, Jackson ME, Mackey TK, Hattangadi-Gluth JA. Distribution and patterns of industry-related payments to oncologists in 2014. J Natl Cancer Inst. 2016;108(12):djw163.

10. Robbins NM, Meyer MJ, Bernat JL. Scope and nature of financial conflicts of interest between neurologists and industry: 2013-2016. Neurology. 2019;93(10):438-49.

11. Jaiswal D, Checketts JX, Vassar M. Industry payments in cardiology: a cross-sectional analysis of Open Payments data. J Am Osteopath Assoc. 2018;118(12):781-7.

12. Na X, Guo H, Zhang Y, Shen L, Wu S, Li J. Mining Open Payments data: analysis of industry payments to thoracic surgeons from 2014-2016. J Med Internet Res. 2018;20(11):e11655.

13. Slentz DH, Nelson CC, Lichter PR. Characteristics of industry payments to ophthalmologists in the Open Payments Database. JAMA Ophthalmol. 2019;137(9):1038-44.

14. Durrani I, Ji YD, Peacock ZS. Do speakers fully disclose potential conflicts of interest in oral and maxillofacial surgery? J Oral Maxillofac Surg. 2020;78(10): 1669-73

15. Saleh RR, Majeed H, Tibau A, Booth CM, Amir E. Undisclosed financial conflicts of interest among authors of American Society of Clinical Oncology clinical practice guidelines. Cancer. 2019;125(22):4069-75.

16. Wright MR, Frye L, Vo Solis $\mathbf{L}$, et al. Evaluating financial conflicts of interest among contributors to clinical practice guidelines of the American College of Obstetricians and Gynecologists. J Am Osteopath Assoc. 2020; 120(7):462-70.

17. Haque W, Alvarenga M, Hsiehchen D. Nonresearch pharmaceutical industry payments to oncology physician editors. Oncologist. 2020;25(6):e986-9.

18. Wong VSS, Avalos LN, Callaham ML. Industry payments to physician journal editors. PLoS One. 2019;14(2):e0211495.

19. Moynihan R, Albarqouni L, Nangla C, Dunn AG, Lexchin J, Bero L. Financial ties between leaders of influential US professional medical associations and industry: cross sectional study. BMJ. 2020;369:m1505.
20. DeJong C, Aguilar T, Tseng CW, Lin GA, Boscardin WJ, Dudley RA. Pharmaceutical industry-sponsored meals and physician prescribing patterns for Medicare beneficiaries. JAMA Intern Med. 2016;176(8):1114-22. Erratum in: JAMA Intern Med. 2016;176(9):1411 2 .

21. Ornstein C, Tigas M, Jones R. Now there's proof: docs who get company cash tend to prescribe more brand-name meds. ProPublica [Internet]. 2016 Mar 17 [cited 2021 Mar 4]. Available from: https://www.propublica. org/article/doctors-who-take-company-cash-tend-to-prescribe-morebrand-name-drugs.

22. Sharma M, Vadhariya A, Johnson ML, Marcum ZA, Holmes HM. Association between industry payments and prescribing costly medications: an observational study using Open Payments and Medicare Part D data. BMC Health Serv Res. 2018;18(1):236.

23. Fleischman W, Agrawal S, King M, et al. Association between payments from manufacturers of pharmaceuticals to physicians and regional prescribing: cross sectional ecological study. BMJ. 2016;354:i4189.

24. Zezza MA, Bachhuber MA. Payments from drug companies to physicians are associated with higher volume and more expensive opioid analgesic prescribing. PLoS One. 2018;13(12):e0209383.

25. Wilson M. The Sunshine Act: commercial conflicts of interest and the limits of transparency. Open Med. 2014;8(1):e10-3.

26. Boyd EA, Cho MK, Bero LA. Financial conflict-of-interest policies in clinical research: issues for clinical investigators. Acad Med. 2003;78(8):769-74.

27. Osborn M, Day R, Komesaroff $\mathbf{P}$, Mant A. Do ethical guidelines make a difference to decision-making? Intern Med J. 2009;39(12):800-5.

28. Rachal M, Lim D. Sunlight doesn't dent industry funding to doctors over half-decade. MedTech Dive [Internet]. 2019 Dec 12 [cited 2021 Mar 4]. Available from: https://www.medtechdive.com/news/sunlight-doesntdent-industry-funding-to-doctors-over-half-decade/568228/.

29. Horstman AA, Niziol LM, Chimonas S, Lichter PR. Association of mandatory disclosure policies and laws with physician-industry financial relationships. JAMA Ophthalmol. 2019;137(5):523-30.

30. Cain DM, Loewenstein G, Moore DA. The dirt on coming clean: perverse effects of disclosing conflicts of interest. J Leg Stud. 2005;34(1):1-25.

31. Werner RM, Asch DA. The unintended consequences of publicly reporting quality information. JAMA. 2005;293(10):1239-44.

32. Pham-Kanter G, Mello MM, Lehmann LS, Campbell EG, Carpenter D. Public awareness of and contact with physicians who receive industry payments: a national survey. J Gen Intern Med. 2017;32(7):767-74.

33. Iyer S, Yoo JS, Jenkins NW, et al. All disclosure is good disclosure: patient awareness of the Sunshine Act and perceptions of surgeonindustry relationships. Clin Spine Surg. 2020;33(3):E96-100.

34. Hwong AR, Sah S, Lehmann LS. The effects of public disclosure of industry payments to physicians on patient trust: a randomized experiment. J Gen Intern Med. 2017;32(11):1186-92.

35. Hampson LA, Agrawal M, Joffe S, Gross CP, Verter J, Emanuel EJ. Patients' views on financial conflicts of interest in cancer research trials. N Engl J Med. 2006;355(22):2330-7.

36. Basken P. Why disclosure policies don't discourage academe's drug salesmen. Chronicle of Higher Education [Internet]. 2017 Jul 3 [cited 2021 Mar 4]. Available from: https://www.chronicle.com/article/whydisclosure-policies-dont-discourage-academes-drug-salesmen/.

37. Sah S, Loewenstein G. Nothing to declare: mandatory and voluntary disclosure leads advisors to avoid conflicts of interest. Psychol Sci. 2014;25(2):575-84.

38. Epstein AJ, Busch SH, Busch AB, Asch DA, Barry CL. Does exposure to conflict of interest policies in psychiatry residency affect antidepressant prescribing? Med Care. 2013;51(2):199-203.

39. King M, Essick C, Bearman P, Cole J, Ross JS. Medical school gift restriction policies and physician prescribing of newly marketed psychotropic medications: difference-in-differences analysis. BMJ. 2013;346:f264.

40. McCormick BB, Tomlinson G, Brill-Edwards P, Detsky AS. Effect of restricting contact between pharmaceutical company representatives and internal medicine residents on posttraining attitudes and behavior. JAMA. 2001;286(16):1994-9.

41. Brennan TA, Rothman DJ, Blank L, et al. Health industry practices that create conflicts of interest: a policy proposal for academic medical centers. JAMA. 2006;295(4):429-33.

42. Committee on Standards for Developing Trustworthy Clinical Practice Guidelines, Board on Health Care Services, Institute of Medicine of the National Academies. Clinical practice guidelines we can trust. Graham R, Mancher M, Miller Wolman D, Greenfield S, Steinberg E, editors. Washington (DC): National Academies Press; 2011. 290 p. 
43. Neuman J, Korenstein D, Ross JS, Keyhani S. Prevalence of financial conflicts of interest among panel members producing clinical practice guidelines in Canada and United States: cross sectional study. BMJ. 2011;343:d5621.

44. McMahon GT. Accreditation rules safeguard continuing medical education from commercial influence. J Med Ethics. 2016;42(3):171.

45. Fugh-Berman A, Hogenmiller A. CME stands for commercial medical education: and ACCME still won't address the issue. J Med Ethics. 2016;42(3):172-3.

46. Society of General Internal Medicine. Policy on acceptance and disclosure of external funds. Available at: https://www.sgim.org/File\%20Library/SGIM/About\%20Us/Policies/External-Funds-Policy-approved-amendment-November-2018.pdf. Accessed March 4, 2021.
47. Christie T. Reformers resist aggressive drug marketing tactics. RegisterGuard [Internet]. 2008 Mar 2 [cited 2021 Mar 4]. Available from: https:// www.cunninghamgroupins.com/reformers-resist-aggressive-drug-marketing-tactics.

48. College of Family Physicians of Canada. Management of relationships with the health care/pharmaceutical industry: the 2018/19 HPI report September 2020 [Internet]. College of Family Physicians of Canada; 2020 Sep [cited 2021 Mar 4]. 11 p. Available from: https://www.cfpc.ca/CFPC/ media/PDF/HPI-Report-2020-ENG-FINAL.pdf.

Publisher's Note: Springer Nature remains neutral with regard to jurisdictional claims in published maps and institutional affiliations. 